\title{
GCU
}

Glasgow Caledonian

University

University for the Common Good

\section{Effect of ambient temperature on the human tear film}

\author{
Abusharha, Ali A.; Pearce, E. Ian; Fagehi, Raied
}

Published in:

Eye and Contact Lens: Science and Clinical Practice

DOI:

10.1097/ICL.0000000000000210

Publication date:

2016

Document Version

Author accepted manuscript

Link to publication in ResearchOnline

Citation for published version (Harvard):

Abusharha, AA, Pearce, El \& Fagehi, R 2016, 'Effect of ambient temperature on the human tear film', Eye and Contact Lens: Science and Clinical Practice, vol. 42, no. 5, pp. 308-312.

https://doi.org/10.1097/ICL.0000000000000210

\section{General rights}

Copyright and moral rights for the publications made accessible in the public portal are retained by the authors and/or other copyright owners and it is a condition of accessing publications that users recognise and abide by the legal requirements associated with these rights.

Take down policy

If you believe that this document breaches copyright please view our takedown policy at https://edshare.gcu.ac.uk/id/eprint/5179 for details of how to contact us. 


\section{Effect of ambient temperature on the human tear film}

Ali. A. Abusharha ${ }^{1}$, PhD, E. Ian Pearce ${ }^{2}$, PhD, Raied Fagehi, ${ }^{l}$ PhD

1.Department of Optometry and Vision sciences King Saud University, Saudi Arabia

2. School of health and life sciences, Glasgow Caledonian University, United Kingdom.

\section{Correspondence}

Ali.A. Abusharha

King Saud University, Riyadh 12372

FAX: 01413313387

Tel: 00966114693543

Email: aabusharha@ksu.edu.sa

\section{E.Ian Pearce}

70 Cowcaddence Road

Glasgow G4 0BA

FAX: 01413313387

Tel: 01413318201

Email: E.I.Pearce@gcu.ac.uk

Raied Fagehi

King Saud University, Riyadh 12372

FAX: 01413313387

Tel: 00966114693543

Email: rfagehi@ksu.edu.sa

\section{Acknowledgement}

The authors extend their appreciation to the college of Applied Medical Sciences Research Centre and the Deanship of Scientific Research at King Saud University for its funding for this research. 


\section{Effect of ambient temperature on the human tear film}

\section{Abstract}

3 Purpose: During everyday life the tear film is exposed to a wide range of ambient

4 temperatures. This study aims to investigate the effect of ambient temperature on tear film 5 physiology.

6 Method: A Controlled Environment Chamber (CEC) was used to create different ambient

7 temperatures $\left(5^{\circ} \mathrm{C}, 10^{\circ} \mathrm{C}, 15^{\circ} \mathrm{C}, 20^{\circ} \mathrm{C}, 25^{\circ} \mathrm{C}\right)$ at a constant relative humidity of $40 \%$. Subjects

8 attended for two separate visits and were exposed to $25^{\circ} \mathrm{C}, 20^{\circ} \mathrm{C}$ and $15^{\circ} \mathrm{C}$ at one visit and to

$9 \quad 10^{\circ} \mathrm{C}$ and $5^{\circ} \mathrm{C}$ at the other visit. The subjects were exposed to each room temperature for 10

10 minutes before investigating tear film parameters. The order of the visits was random. Tear

11 physiology parameters assessed were tear evaporation rate, non-invasive tear breakup time

12 (NIBUT), lipid layer thickness (LLT), and ocular surface temperature (OST). Each parameter

13 was assessed under each condition.

14 Result: A three-fold increase in tear evaporation rate was observed as ambient temperature increased to $25^{\circ} \mathrm{C}(p=0.00)$. The mean evaporation rate increased from $0.056 \mu 1 / \mathrm{min}$ at $5^{\circ} \mathrm{C}$, to $0.17 \mu \mathrm{l} / \mathrm{min}$ at $25^{\circ} \mathrm{C}$. The mean NIBUT increased from $7.31 \mathrm{sec}$ at $5^{\circ} \mathrm{C}$ to $12.35 \mathrm{sec}$ at $25^{\circ} \mathrm{C}(p=0.01)$. A significant change in LLT was also observed $(p=0.00)$, LLT median ranged between to 20 to $40 \mathrm{~nm}$ at 5 and $10{ }^{\circ} \mathrm{C}$ and increased to 40 and $90 \mathrm{~nm}$ at 15,20 and

$1925^{\circ} \mathrm{C}$. Mean reduction of $4^{\circ} \mathrm{C}$ OST was observed as ambient temperature decreased from 25 to $5^{\circ} \mathrm{C}$.

21 Conclusion: Ambient temperature has a considerable effect on human tear film characteristics. Tear evaporation rate, tear lipid layer thickness, tear stability and ocular surface temperature were considerably affected by ambient temperature. Chronic exposure to 
24 low ambient temperature would likely result in symptoms of dry eye and ultimately ocular 25 surface disorders.

26 Keywords: Tear film, dry eye, environmental factors, ambient temperature.

27 
28 Tear film function and structure can be altered by many different factors. Some of these

29 factors are internal disorders such as insufficient tear production, meibomian gland

30 dysfunction, hormonal changes and autoimmune disease. ${ }^{1}$ In addition, as the tear film is

31 directly exposed to the ambient environment, tear film thinning and instability can be caused

32 by external factors such as ambient temperature, humidity, air flow and pollution. ${ }^{2,3}$ Recently,

33 researchers have shown an increased interest in the effect of the ambient environment on

34 human body tissues. ${ }^{4,5}$ Symptoms including ocular itching, stuffy nose, dry throat,

35 breathlessness, dry skin and headaches have been frequently reported by individuals working

36 in adverse environmental conditions. ${ }^{6,7}$

37 Ambient temperature is an external environmental factor that could affect the tear film. In 38 addition to outdoor ambient temperature, the thermal conditions of commercial buildings and

39 indoor workplace are not-well controlled. Unfortunately, to date, little attention has been paid

40 to the relationship between the change in ambient temperature and tear film behaviour. One

41 previous study has suggested that a relationship exists between tear film and atmospheric

42 temperature. ${ }^{8}$ A significant difference in tear stability and production was found in normal

43 subjects living in places characterized by a warm climate compared with those living in cold

44 places. $^{8}$ Another in vitro study investigating the effect of temperature on tear evaporation

45 found that there was a threefold increase in evaporation rate as ambient temperature increased

46 from 25 to $34^{\circ} \mathrm{C} .{ }^{9}$ The relationship between ocular surface temperature and room temperature

47 has been well documented. ${ }^{10-13}$ There has been little discussion about the effect of ambient

48 temperature on tear film parameters. Most researchers to date tended to focus on the relation

49 between OST and ambient temperature ignoring its effect on tear film parameters and the

50 inter-relationship between these parameters. Therefore, the aim of this study was to determine 
51 the effect of ambient temperature on ocular surface temperature and its effect on the ocular surface and tear film parameters. The inter-relationship between tear parameters and OST will be monitored at across range of different temperatures.

Method

55 Ethical approval was obtained from the Glasgow Caledonian University Human Ethics

56 Committee. Subjects were healthy normals with no evidence of dry eye. Inclusion criteria 57 was Ocular Surface Disease Index (OSDI) ${ }^{14}$ score of less than 12 and NITBUT of more than 5810 seconds using HIRCAL grid. ${ }^{15}$ Twelve healthy normal subjects ( 3 female, 9 male, mean \pm $59 \operatorname{Sd} 29.4 \pm 2.4$ years) with no current ocular diseases or surgery were enrolled in this study.

60 As the control of ambient temperature and humidity was required during the experiment, a 61 controlled environment chamber (CEC) (Weiss-Gallenkamp Ltd, Loughborough, UK) was 62 used. ${ }^{16}$ The room temperature was set at 5 and $10^{\circ} \mathrm{C}$ on one visit. On the other visit, the CEC was set at temperatures of 15,20 and then $25^{\circ} \mathrm{C}$.

64 The subjects were divided into two groups (Group A and Group B). The order of visits was randomised in a cross-over design where the subjects in group A were exposed to a temperature of 25,20 and $15^{\circ} \mathrm{C}$ and then exposed to 10 and $5^{\circ} \mathrm{C}$ ambient temperatures.

67 Group B subjects were exposed to ambient temperature of 10 and $5^{\circ} \mathrm{C}$, then at their second 68 visit they were exposed to 25,20 and $15^{\circ} \mathrm{C}$. The relative humidity inside the CEC was maintained at $40 \%$ during the assessment of the tear film during the two visits. In order to minimize the possible implications of two visits, tear parameters assessments were conducted

71 late morning and afternoon (after 11am) in both visits to avoid the effect of diurnal variation 72 in ocular surface temperature. 
73 A previous study investigating tear film parameters under different environmental conditions

74 found a 6 to 10 minutes adaptation time was needed for the subjects before conducting ocular

75 surface investigations. ${ }^{17}$ In this study, for the purpose of room temperature adaption, the

76 subjects were exposed to each environmental condition for 10 minutes before starting

77 investigations tear parameter.

The parameters assessed in this study were lipid layer thickness (LLT), tear evaporation rate (EVAP) non-invasive tear break-up time (NITBUT) and ocular surface temperature (OST).

Tear break-up time and tear lipid layer thickness were assessed non-invasively by Keeler

Tearscope Plus (Keeler Ltd, Windsor, UK). The Guillon and Guillon grading system was

82 utilized to estimate the thickness of the tear lipid layer. ${ }^{18}$ Tear evaporation rate was measured using a Servo-Med Evaporimeter (Servo Med, Varberg, Sweden). ${ }^{19}$ A change in ocular surface temperature during exposure to the different ambient temperature was monitored with FLIR System ThermaCAM P620 (FLIR Systems, Surry, UK). ${ }^{16}$ A circle of approximately 4 $\mathrm{mm}$ diameter was placed at the estimated centre of the cornea and the mean temperature of

87 this area was calculated. Thermal images of ocular surface were continuously recorded for one minute at frame rate of $30 \mathrm{~Hz}$. All temperature measurements were then exported to an Excel spreadsheet and 600 thermal values were selected with exclusion of the reading recorded immediately post-blink.

91 Variables were tested for normality using a Kolmogorov-Smirnov test. A repeated measure ANOVA and Tukey's post-hoc test were applied for normally distributed data while the ordinal and data with non-normal distribution were ‘analysed using Friedman's test and post-

94 hoc Wilcoxon rank-sum test. Correlation between tear parameters was assessed using

95 Pearson's test and Spearman's test for the data with normal and non-normal distribution 96 respectively. 


\section{$97 \underline{\text { Result }}$}

\section{$98 \quad$ Lipid layer thickness}

99 Changes in lipid layer thickness were found as temperature was altered (Figure 1A). The

100 median grade of lipid layer thickness observed was grade $2(20-40 \mathrm{~nm})$ at 5 and $10^{\circ} \mathrm{C}$ and

101 increased to grade $3(40-90 \mathrm{~nm})$ at 15,20 and $25^{\circ} \mathrm{C}$. Wilcoxon rank-sum test has shown that 102 the lipid layer thickness was significantly thinner at $5^{\circ} \mathrm{C}$ in contrast to other ambient 103 temperatures $(p<0.05)$. Also a significant difference was observed at $10^{\circ} \mathrm{C}$ compared to lipid 104 thickness at $20(p=0.006)$ and $25^{\circ} \mathrm{C}(p=0.007)$. No significant change in lipid layer thickness 105 was noticed when room temperature was changed from 20 to $25^{\circ} \mathrm{C}$.

\section{Tear evaporation rate}

107 The box plot of tear evaporation indicates that, as the ambient temperature was increased, the tear evaporation rate also increased (Figure 1B). A three-fold increase in tear evaporation was

109 observed as the ambient temperature increased from 5 to $25^{\circ} \mathrm{C}$. The mean evaporation rate 110 was $0.056 \mu \mathrm{l} / \mathrm{min}\left(20.11 \mathrm{~g} / \mathrm{m}^{2} / \mathrm{h}\right)$ at $5^{\circ} \mathrm{C}$, but increased dramatically to $0.17 \mu \mathrm{l} / \mathrm{min}(62.62$

$111 \mathrm{~g} / \mathrm{m}^{2} / \mathrm{h}$ ) when the room temperature was raised to $25^{\circ} \mathrm{C}$. Tukey's post-hoc test has been done

112 for evaporation rate data. Statistically significant differences were observed in evaporation 113 rate at $5^{\circ} \mathrm{C}$ when compared to $20^{\circ} \mathrm{C}(p=0.013)$ and $25^{\circ} \mathrm{C}(p=0.001)$.

\section{NITBUT}

115 Changes in tear film stability are shown in Figure $1 \mathrm{C}$. At a room temperature of $5^{\circ} \mathrm{C}$ a 116 significant reduction was found in NITBUT compared to those values obtained at all other 117 temperatures $\left(10,15,20\right.$ and $\left.25^{\circ} \mathrm{C}\right),(p<0.05)$. The mean NITBUT values were 7.31 sec and $118 \quad 12.35 \mathrm{sec}$ at $5^{\circ} \mathrm{C}$ and $25^{\circ} \mathrm{C}$ respectively. Measurements of NITBUT were statistically 
119 analysed using Tukey's post-hoc test. A significant change in NITBUT was observed at $10^{\circ} \mathrm{C}$

120 when compared to $20(p=0.002)$ and $25^{\circ} \mathrm{C}(p=0.001)$.

\section{Ocular surface temperature}

122 Ocular surface temperature also showed a significant change $(p<0.05)$. From the data in

123 figure 1D it is apparent that there is a clear trend of decreasing OST as ambient temperature

124 decreased. A reduction of $4^{\circ} \mathrm{C}$ OST was observed as ambient temperature decreased by $20^{\circ} \mathrm{C}$ 125 (from 25 to $5^{\circ} \mathrm{C}$ ).

126 Correlation tests were applied to determine the relationship between tear parameters as 127 temperature was altered. Data from all temperatures were combined and analyzed using 128 either Persons's $(R)$ for normally distributed data or Spearman's (rho) correlation tests for 129 ordinal and data with non-normal distribution. In Figure 2A a scatter plot shows a positive 130 relationship between ocular surface temperature and evaporation rate $(r=0.45, p<0.05)$. 131 Also, a significant correlation noted between evaporation rate and tear break-up time $(r=$ $1320.32, p<0.001$ (Figure 2B). Tear evaporation was also showed a negative relationship with 133 lipid layer thickness ( $r h o=0.43, p<0.001$ ) (Figure $2 \mathrm{C}$ ). Also a significant correlation 134 between lipid layer thickness and tear film stability was found ( $r h o=0.49, p<0.001$ ) (Figure 135 2D).

\section{Discussion}

137 The purpose of this study was to examine the effect of ambient temperature on tear film and

138 the ocular surface. Tear stability, lipid layer thickness, evaporation rate and ocular surface

139 were measured over a range of temperatures to evaluate the relationship between these

140 parameters and temperature. In addition, the inter-relationship between these parameters was 
141 examined to see how these are linked. This is an attempt to understand the relationship

142 between these parameters in normal physiological conditions.

143 The evidence from this study suggests that the tear film lipid layer is affected significantly at 144 low temperatures. It shows interference patterns characteristic of a thinner tear film after 145 exposure to a temperature of less than $10^{\circ} \mathrm{C}$. Hydrocarbon chains make up most of the lipid 146 mass. It has been shown that lipid hydrocarbon structural order is affected by temperature. ${ }^{20}$

147 Moreover, a relationship between lipid hydrocarbon chain order and meibomian lipid 148 delivery to the lid margin has been found. ${ }^{21}$ The melting range of meibomian lipids has been 149 shown to be between 32.50 and $35^{\circ} \mathrm{C} .^{22,23}$ Previous work has shown that meibomian lipids 150 become thicker as the ocular surface and eyelid temperature drops below $33^{\circ} \mathrm{C}$, which may 151 impede the normal delivery of meibomian lipids to the ocular surface. ${ }^{24}$ In addition to 152 delivery, it has been shown that spreading over the tear film of meibomian lipids is also 153 affected by temperature. ${ }^{23}$

154 In the current study ocular surface temperature of less than $32{ }^{\circ} \mathrm{C}$ was observed after exposure 155 to a room temperature of less than $10^{\circ} \mathrm{C}$. Therefore, the changes in thickness and appearance 156 of the tear film lipid layer observed in this study are likely to be due to variation in delivery 157 and spread of meibomian lipid over the ocular surface.

158 A change in tear evaporation rate was observed when the ambient temperature changed. The evaporation rate increased as the temperature increased. The mean evaporation rate at $25^{\circ} \mathrm{C}$

160 was double that observed at $10^{\circ} \mathrm{C}$, and triple the values recorded at $5^{\circ} \mathrm{C}$. Box plots of 161 evaporation rate at $25^{\circ} \mathrm{C}$ show that a quarter of participants had an evaporation rate 162 characteristic of dry eye patients (evap $\left.>0.23 \mu 1 / \mathrm{min}^{25}\right)$. The lipid layer plays a critical role in 163 controlling tear film evaporation. However, although a thin lipid layer was observed at 5 and $16410^{\circ} \mathrm{C}$, the evaporation rate was low in the cold environment, meaning that there may be 
165 another factor apart from the meibomian lipid that could affect the evaporation of tears.

166 Decreased ambient temperature and OST result in decreasing the water molecule energy at

167 the ocular surface, thus fewer molecules will be able to leave the ocular surface, which leads

168 to a decrease in the evaporation rate. ${ }^{26}$ Also, water-holding capacity of the atmosphere

169 decreases with decreasing ambient temperature, therefore the atmosphere can hold very little

170 moisture. ${ }^{27}$ These two factors working together may explain the reduction in evaporation rate

171 in cold conditions and the negative relationship observed between lipid layer thickness and

172 evaporation rate at low temperatures.

173 This study shows significant changes in tear stability at low temperatures. The mean

174 NITBUT value at $5^{\circ} \mathrm{C}$ was 7.31 seconds. It is accepted that tear film with a break-up time of

175 less than 10 seconds is considered an unstable tear film (moderate dry eye - grade 2$).{ }^{1}$

176 Moreover, recent work has demonstrated that the mean interblink interval (IBI) is 7.5

177 seconds. ${ }^{28}$ In the current work, a NITBUT value of less than the typical IBI was recorded at

17810 and $5^{\circ} \mathrm{C}$, that may result in possible repeated exposure of the ocular surface. Consequently,

179 frequent ocular surface exposure could lead to the development of the signs and symptoms of

180 dry eye and visual disturbances. Previous studies have shown that tear stability is changed as

181 tear film exposed to different ambient temperature. ${ }^{8}$ Several studies have revealed that tear

182 stability is the function of lipid layer integrity. ${ }^{29-32}$ A change in the tear film lipid layer in a

183 cold environment described earlier could be the reason behind the instability of tear film

184 noted in this study.

185 In this study, it was found that ocular surface temperature decreased significantly as the 186 ambient temperature decreased in $5^{\circ} \mathrm{C}$ steps. Pairwise comparison showed a significant

187 difference in OST in all environmental conditions with the exception of that between 15 and $18820^{\circ} \mathrm{C}(p=0.093)$. In the current study the mean change in central ocular surface temperature 
was $0.18 \pm 0.40^{\circ} \mathrm{C}$ for each $1{ }^{\circ} \mathrm{C}$ change in room temperature. A drop between 0.15 and $0.21^{\circ} \mathrm{C}$ in human ocular surface temperature for each $1{ }^{\circ} \mathrm{C}$ reduction in ambient temperature has been

191 reported. ${ }^{33,34}$ It has been suggested that a decrease in ambient temperature could result in

192 significant reduction in corneal metabolic activity, which could be the reason behind the

193 reduction in corneal temperature. ${ }^{35}$ However, it should be considered that metabolic rate may

194 be not affected immediately with decreasing ambient temperature, therefore immediate change in OST could be resulted from another factor such as increasing evaporation rate.

\section{Conclusion}

197 This study has shown that ambient temperature influences tear film parameters. The current

198 findings add to our understanding of the inter-relationship between tear film parameters and

199 the physiological linkage between these parameters. The stability of tear film and lipid layer

200 thickness were adversely affected at room temperatures of less than $10^{\circ} \mathrm{C}$. NITBUT of less

201 than the suggested IBI was recorded which may lead to exposure and to ocular surface pathology and a visual disturbance.

203 The evaporation rate showed a significant increase when the tear film was exposed to a room

204 temperature of more than $20^{\circ} \mathrm{C}$, and values of higher than the cut-off value of normal tear 205 film were observed at a room temperature of $25^{\circ} \mathrm{C}$.

206 Therefore, the effect of low or high ambient temperature on the tear film should not be

207 neglected by people who work outdoors and spend a long time in adverse climate conditions

208 or individual who play winter sports such as skiing and ice skating. In the same way, indoor

209 workplaces need to be able to be maintained at a healthy and comfortable temperature range

210 to ensure ocular comfort and well-being. 
212 1. Lemp MA, Baudouin C, Baum J, et al. The definition and classification of dry eye

213 disease: Report of the Definition and Classification Subcommittee of the international Dry 214 Eye WorkShop Ocul Surf 2007;5:75-92.

215 2. Gonzalez-Garcia MJ, Gonzalez-Saiz A, de la Fuente B, et al. Exposure to a controlled 216 adverse environment impairs the ocular surface of subjects with minimally symptomatic dry 217 eye. Invest Ophthalmol Vis Sci 2007;48:4026-32.

2183 3. Sato M, Fukayo S, Yano E. Adverse environmental health effects of ultra-low relative humidity indoor air. J Occup Health 2003;45:133-6.

220 4. Norback D, Lindgren T, Wieslander G. Changes in ocular and nasal signs and symptoms among air crew in relation to air humidification on intercontinental flights. Scandinavian Journal of Work Environment \& Health 2006;32:138-44.

223 5. Reinikainen L, Jaakkola J. Significance of humidity and temperature on skin and upper airway symptoms. Indoor Air 2003;13:344-52.

6. de Magalhaes Rios JL, Boechat JL, Gioda A, dos Santos CY, de Aquino Neto FR, Lapa e Silva JR. Symptoms prevalence among office workers of a sealed versus a non-sealed building: Associations to indoor air quality. Environ Int 2009;35:1136-41.

7. Wolkoff P. "Healthy" eye in office-like environments. Environ Int 2008;34:1204-14.

8. Paschides CA, Stefaniotou M, Papageorgiou J, Skourtis P, Psilas K. Ocular surface and environmental changes. Acta Ophthalmol Scand 1998;76:74-7.

9. Borchman D, Foulks GN, Yappert MC, Mathews J, Leake K, Bell J. Factors Affecting Evaporation Rates of Tear Film Components Measured In Vitro. Eye Contact Lens-Sci Clin Pra 2009;35:32-7.

10. Horven I. Corneal temperature in normal subjects and arterial occlusive disease Acta Ophthalmol (Copenh) 1975;53:863-74.

11. Hata S, Sakata M, Watanabe A, Fujishima H, Tsubota K. Corneal temperature and inter-blinking time. Invest Ophthalmol Vis Sci 1994;35:S999.

12. Girardin F, Orgul S, Erb C, Flammer J. Relationship between corneal temperature and finger temperature. Arch Ophthalmol 1999;117:166-9.

13. Rysa P, Sarvaran.J. Thermography of the eye during cold stress. Acta Ophthalmol (Copenh) 1974;123:234-9.

14. Schiffman RM, Christianson MD, Jacobsen G, Hirsch JD, Reis BL. Reliability and validity of the ocular surface disease index. Arch Ophthalmol 2000;118:615-21.

15. Hirji N, Patel S, Callander M. Human tear film pre-rupture phase time (TP-RPT)- A non-invasive technique for evaluation the pre-corneal tear film using a novel keratometer mire. Ophthalmic Physiol Opt 1989;9:139-42.

16. Abusharha AA, Pearce EI. The Effect of Low Humidity on the Human Tear Film. Cornea 2012;32:429-34.

17. Purslow C, Wolffsohn J. The relation between physical properties of the anterior eye and ocular surface temperature. Optom Vis Sci 2007;84:197-201.

18. Guillon JP. Non-invasive Tearscope Plus routine for contact lens fitting. Cont Lens Anterior Eye 1998;21 Suppl 1:S31-40.

19. Trees GR, Tomlinson A. Effect of Artificial Tear Solutions and Saline on Tear Film Evaporation. Optom Vis Sci 1990;67:886-90.

20. Borchman D, Foulks GN, Yappert MC, Ho DV. Temperature-induced conformational changes in human tear lipids hydrocarbon chains. Biopolymers 2007;87:124-33. 
21. Nagymihalyi A, Dikstein S, Tiffany JM. The influence of eyelid temperature on the delivery of meibomian oil. Exp Eye Res 2004;78:367-70.

259 22. Butovich IA. On the lipid composition of human meibum and tears: comparative 260 analysis of nonpolar lipids. Invest Ophthalmol Vis Sci 2008;49:3779-89.

261 23. Brown SI, Dervichian D. The oils of the meibomian glands: physical and surface characteristics. Arch Ophthalmol 1969;82:537.

24. Butovich IA, Arciniega JC, Wojtowicz JC. Meibomian lipid films and the impact of temperature. Invest Ophthalmol Vis Sci 2010;51:5508-18.

265 25. Tomlinson A, Doane MG, McFadyen A. Inputs and Outputs of the Lacrimal System:

266 Review of Production and Evaporative Loss. Ocul Surf 2009;7:186-98.

267 26. Garai J. Physical model for vaporization. Fluid Phase Equilib 2009;283:89-92.

268 27. Gessert G. Measuring a medium's air space and water holding capacity. Ornamentals 269 Northwest 1976;3:59-60.

270 28. Ousler GW, Hagberg KW, Schindelar M, Welch D, Abelson MB. The Ocular 271 Protection Index. Cornea 2008;27:509-13.

272 29. Blackie CA, Solomon JD, Scaffidi RC, Greiner JV, Lemp MA, Korb DR. The 273 Relationship Between Dry Eye Symptoms and Lipid Layer Thickness. Cornea 2009;28:78927494.

275 30. Isreb MA, Greiner JV, Korb DR, et al. Correlation of lipid layer thickness 276 measurements with fluorescein tear film break-up time and Schirmer's test. Eye 2003;17:7927783.

278 31. Foulks GN. The correlation between the tear film lipid layer and dry eye disease. Surv 279 Ophthalmol 2007;52:369-74.

280 32. Foulks GN, Bron AJ. Meibomian gland dysfunction: a clinical scheme for description, 281 diagnosis, classification, and grading. Ocul Surf 2003;1:107-26.

282 33. Mapstone R. Determinants of corneal temperature. Br J Ophthalmol 1968;52:729-41.

283 34. Morgan PB. Ocular Thermography in Health and Disease [Ph.D. thesis]. Manchester, 284 University of Manchester 1994.

285 35. Freeman R, Fatt I. Environmental influences on ocular temperature. Invest 286 Ophthalmol Vis Sci 1973;12:596-602. 
290 Figure 1. Comparison of the distribution of lipid layers pattern over range of ambient

291 temperature. Thicker lipid pattern was observed in higher room temperature (A). A box plot

292 showing tear evaporation rate (B) measured at 5, 10, 15, 20 and $25^{\circ} \mathrm{C}$. Significant increase in

293 tear evaporation was found as ambient temperature was increased. NITBUT (C) became

294 shorter when tear film was exposed to lower temperature. The tear break up time at $5^{\circ} \mathrm{C}$ was

295 significantly shorter than all other room temperatures. Significant difference was seen in

296 ocular surface temperature (D) between all ambient temperatures with exception of that

297 between 15 and $20^{\circ} \mathrm{C}(n=12, p=0.093)$. The box represents the interquartile range that

298 contains $50 \%$ of the values. The whiskers are lines that extend from the box to the highest

299 and lowest values, excluding outliers (O) that are 1.5 to 3 box lengths from the upper and

300 lower edge of the box and extremes $(*)$ that are more than 3 box lengths. The line across the

301 box indicates the median value. Pairwise significant differences are shown (*)

302 Figure 2.Scatter plot showing correlation between ocular surface temperature and

303 evaporation rate (A), evaporation rate and tear break up time (B), evaporation rate and lipid

304 layer thickness (C), tear break up time and lipid layer thickness(D). 


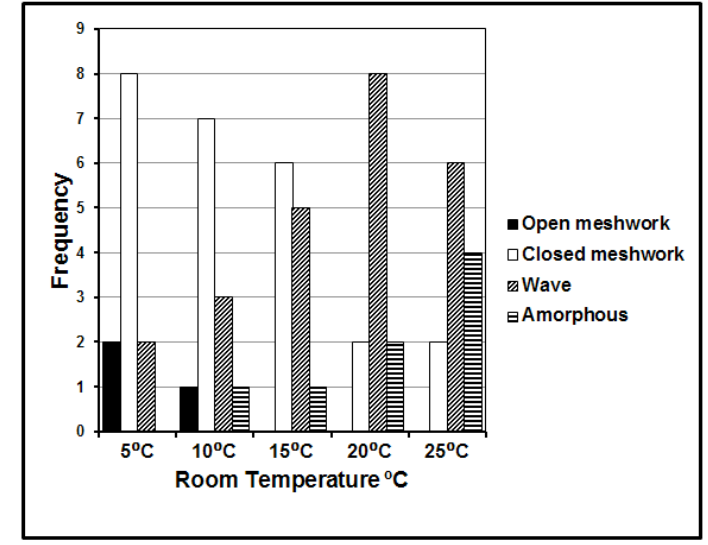

A

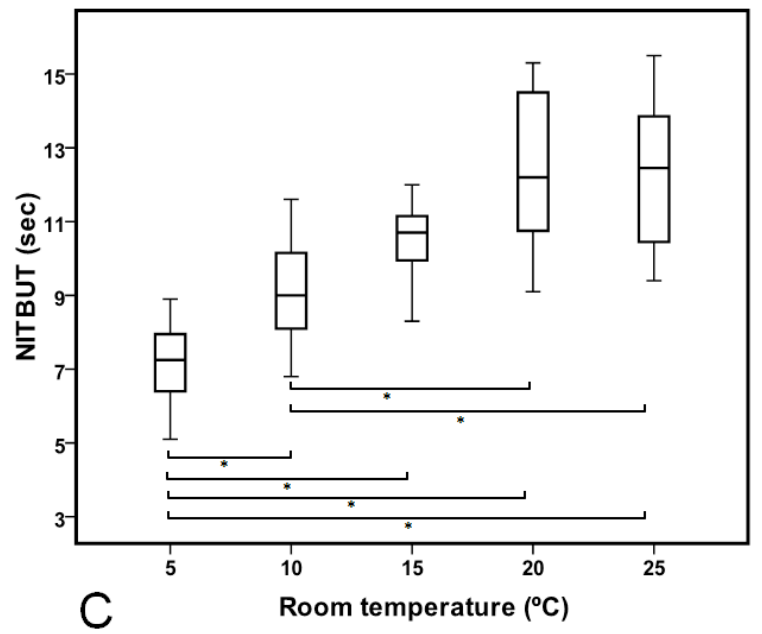

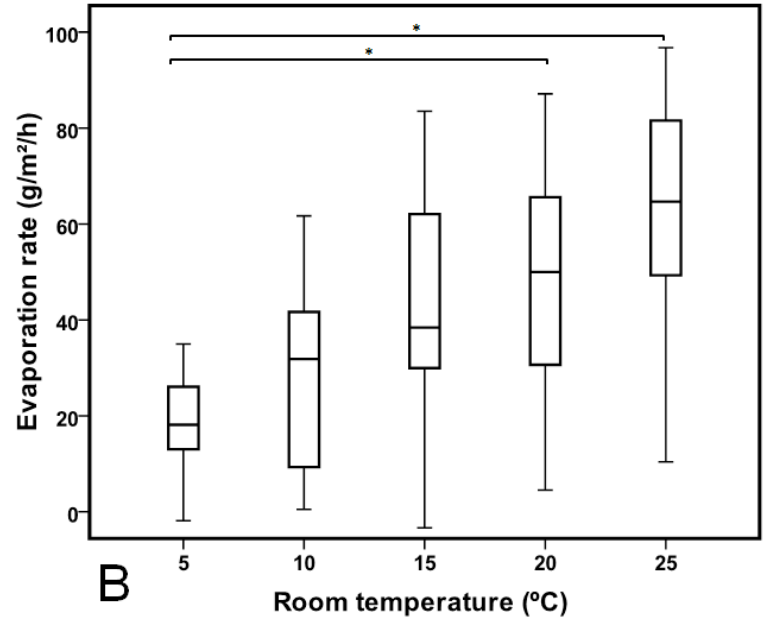

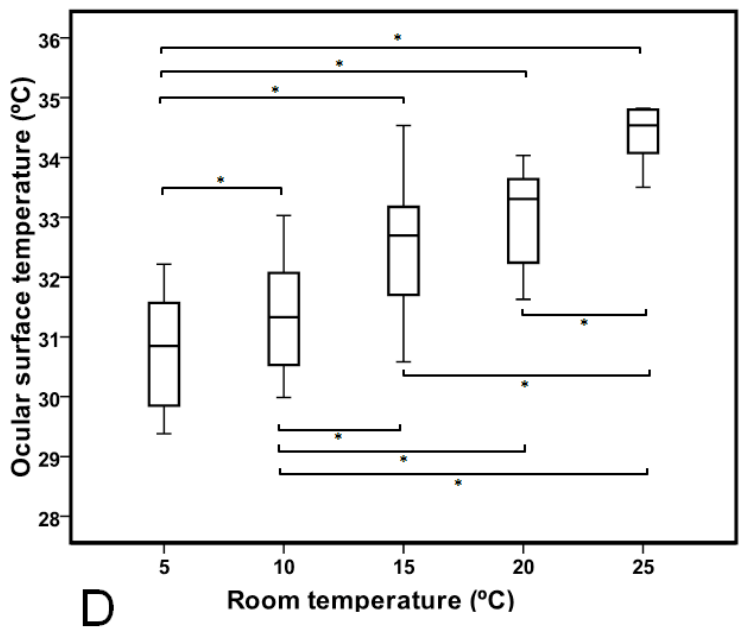

307 Figure 1. Comparison of the distribution of lipid layers pattern over range of ambient

308 temperature. Thicker lipid pattern was observed in higher room temperature (A). A box plot

309 showing tear evaporation rate (B) measured at 5, 10, 15, 20 and $25^{\circ} \mathrm{C}$. Significant increase in

310 tear evaporation was found as ambient temperature was increased. NITBUT (C) became

311 shorter when tear film was exposed to lower temperature. The tear break up time at $5^{\circ} \mathrm{C}$ was

312 significantly shorter than all other room temperatures. Significant difference was seen in

313 ocular surface temperature (D) between all ambient temperatures with exception of that

314 between 15 and $20^{\circ} \mathrm{C}(n=12, p=0.093)$. The box represents the interquartile range that

315 contains $50 \%$ of the values. The whiskers are lines that extend from the box to the highest

316 and lowest values, excluding outliers $(\mathrm{O})$ that are 1.5 to 3 box lengths from the upper and

317 lower edge of the box and extremes $\left(^{*}\right)$ that are more than 3 box lengths. The line across the

318 box indicates the median value. Pairwise significant differences are shown (*) 

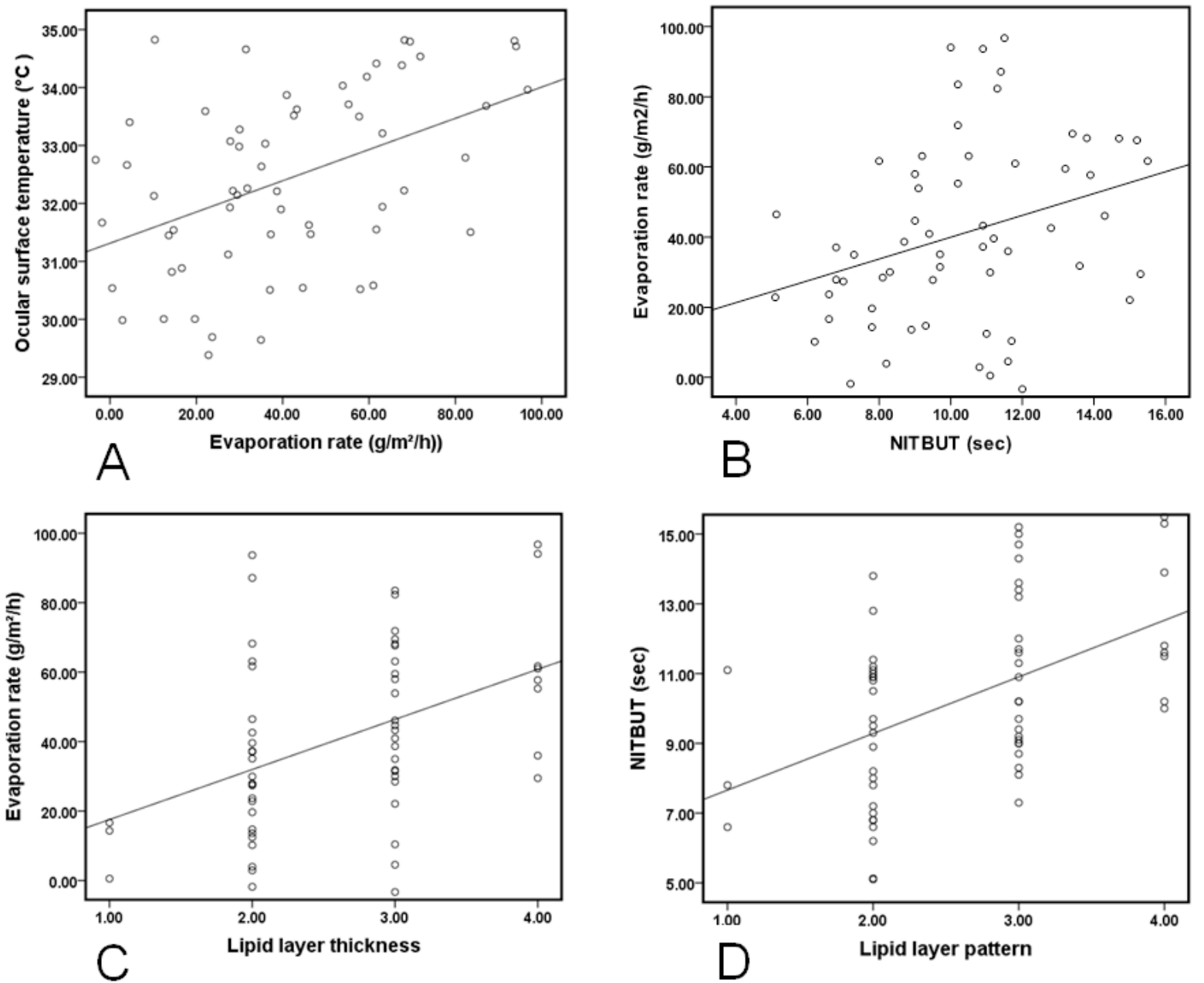

320 Figure 2.Scatter plot showing correlation between ocular surface temperature and

321 evaporation rate (A), evaporation rate and tear break up time (B), evaporation rate and lipid 322 layer thickness (C), tear break up time and lipid layer thickness(D). 